\title{
Trabajo y castigos laborales a los indios de Pamplona del Nuevo Reino de Granada, siglo XVII
}

\section{Resumen}

Este artículo procura examinar cuáles fueron los castigos laborales que infringieron los encomenderos y agentes privados (hacendados, estancieros y mineros) a los indios durante el siglo XVII en la Provincia de Pamplona del Nuevo Reino de Granada. Para ello se han examinado algunas solicitudes y quejas que presentaban los indios. El enfoque adoptado aborda las relaciones entre las condiciones de trabajo y los castigos bajo el régimen de la encomienda, el concierto agrario y las conducciones a las minas de oro (los dos últimos eran tipos de mita en la región). Como resultado se encontraron múltiples referencias a prácticas que acentuaban las disciplinas laborales y la sumisión de los indios en la vida cotidiana. La investigación permite concluir que hubo significativas conexiones entre los castigos, la intensidad de los regímenes de trabajo, las huidas, las enfermedades $y$, en general, el declive demográfico de las comunidades indias.

\section{Palabras clave}

Tesauro: Castigo, condiciones de trabajo, disminución de la población.

Referencia bibliográfica para citar este artículo: García Rincón, Leonardo Fabián. "Trabajo y castigos laborales a los indios de Pamplona del Nuevo Reino de Granada, siglo XVII". Anuario de Historia Regional $y$ de las Fronteras 24.1 (2019): 155-175.

Leonardo Fabián García Rincón: actualmente es candidato a Magíster en Historia de la Universidad Industrial de Santander, Colombia. Historiador de la Universidad Industrial de Santander, Colombia. Docente de ocasional de la Universidad Industrial de Santander, Colombia. Código ORCID: https://orcid. org/0000-0002-4162-1060. Correo electrónico: leotjq12@gmail.com.

\footnotetext{
* El presente trabajo forma parte de un proyecto de investigación denominado "Pueblos de indios de la Provincia de Pamplona, 1600-1800: demografía, conflictos económicos y cristianización”, auspiciado en la condición de beca del Programa de Maestría en Historia de la Universidad Industrial de Santander (UIS), Bucaramanga, Colombia
} 


\title{
Work and Labour Punishments to Indians of Pamplona in the New Kingdom of Granada, Seventeenth Century
}

\begin{abstract}
This article aims to examine the labour punishments, which were imposed on Indians by encomenderos and private agents (landowners, ranchers and miners) during the seventeenth century in the Pamplona Province of the New Kingdom of Granada. With that purpose, it has been examined some requests and complaints presented by Indians. The approach adopted addresses the relationships between working conditions and punishments under regime of encomienda, agrarian agreement and conductions to gold mines (the last two were types of mita in the region). As a result, they were found multiple references to practices, which accentuated labour disciplines and submission of Indians in everyday life. The research enables to conclude that there were significant connections between punishments, intensity of the work regimes, escapes, diseases and, in general, the demographic decline of the Indian communities.
\end{abstract}

Keywords

Thesaurus: Punishment, Working Conditions, Population Decrease.

\section{Trabalho e punições trabalhistas aos índios de Pamplona do Novo Reino de Granada, século XVII}

\section{Resumo}

Este artigo tenta examinar quais foram as punições trabalhistas que os encomenderos e agentes privados (latifundiário, estancieiros e mineiros) infringiram nos índios durante o século XVII na Província de Pamplona, Novo Reino de Granada. Para isso, alguns pedidos e reclamações apresentados pelos índios foram examinados. O foco adotado aborda as relações de trabalho e punições sob o regime da Encomienda, o Acordo agrário e as Conduções às minas de ouro (as duas últimas foram tipos de mita na região). Como resultado, foram encontradas múltiplas referências práticas que acentuaram as disciplinas do trabalho e a submissão dos índios na vida cotidiana. A pesquisa permite concluir que houve conexões significativas entre as punições, a intensidade dos regimes de trabalho, as fugas, as doenças e, em geral, o declínio demográfico das comunidades indígenas.

\section{Palavras-chave}

Tesauro: Punição, condições de trabalho, diminuição da população. 


\section{El problema desde la historiografía}

Existen importantes trabajos que relatan e intentan explicar la magnitud del declive demográfico indígena en todo el continente americano a partir del siglo XVI, centrando la atención en los virreinatos de Nueva España y Perú. Sobresalen los trabajos de Woodrow Borah y Sherburne F. Cook, ${ }^{1}$ Noble David Cook, ${ }^{2}$ William M. Denevan $^{3}$ y Massimo Livi Bacci. ${ }^{4}$ En los textos de estos autores, las enfermedades y las guerras de conquistas han sido las principales causas explicativas del fenómeno del declive. Sin negar su eventual importancia, estos dos hechos históricos han deslucido en cierta medida el peso del impacto de los regímenes de trabajo (y de un factor de vital valor como los castigos). Un testimonio en este sentido lo expuso Charles Gibson cuando escribió las siguientes líneas:

En tiempo recientes, los rigores del trato de los españoles y los accesos de enfermedades parecen ofrecer las explicaciones más probables. Pero la opinión de que el maltrato de los indígenas por los españoles fue principalmente responsable de la disminución en gran escala de la población ha perdido ahora gran parte de su aceptación primitiva; entre todas las causas, la enfermedad epidémica es ahora reconocida como esencial. ${ }^{5}$

Valga decir que el propósito de Gibson era relatar en qué medida las instituciones sociales y económicas impuestas por los españoles en la Nueva España habrían generado desequilibrios en la población nativa. En este sentido describía como, desde principio del siglo XVII, los trabajos agrícolas, las obras públicas en la ciudad y la imposición del tributo presionaban cada vez a las comunidades indígenas. Esto había llevado a una mayor competencia entre los españoles por los trabajadores indígenas y actos ilegales, de modo que los primeros "secuestraban a los trabajadores, los golpeaban, se negaban a pagarles, embargaban sus alimentos y ropas para impedir que escaparan". A ello se habría sumado el sistema de los obrajes, donde el trabajo era duro, el alimento y las condiciones de vida insatisfactorios, y común el abuso físico. ${ }^{6}$ Entiéndase por este último el castigo laboral.

James Lockhart afirmaba que la presencia de los europeos entre los nativos americanos desencadenó una serie de largas epidemias que nada tenía que ver con las

\footnotetext{
1 Sherburne F. Cook y Woodrow Borah, The population of central Mexico in 1548: an analysis of the Suma de Visitas de pueblos (Berkeley: University of California Press, 1960), The Indian population of central Mexico, 1531-1610 (Berkeley: University of California Press, 1960), Ensayos sobre historia de la población: México y el Caribe (México: Siglo XXI, 1977).

${ }^{2}$ Noble David Cook, Demographic Collapse: Indian Peru, 1520-1620 (Cambridge: Cambridge University Press, 1981).

${ }^{3}$ William M. Denevan, The Native population of the Americas in 1492 (Madison: University of Wisconsin Press, 1992).

${ }^{4}$ Massimo Livi Bacci, Los estragos de la conquista: quebranto y declive de los indios de América (Barcelona: Crítica, 2006)

${ }^{5}$ Charles Gibson, Los aztecas bajo el dominio español: 1519-1810 (México: Siglo XXI, 1983) 138.

${ }^{6}$ Gibson 248
} 
intenciones de las partes. Aunque sugería como la disminución demográfica afectó el modo de vida, la organización sociopolítica y los criterios de diferenciación social, no abordó el problema de la organización del trabajo. Con todo, sostenía que se generó una "transformación gradual con profundas continuidades", que mezclaba "conflictos y cooperación, congregación y alejamiento". ${ }^{7}$ Explicación similar expuso Matthew Restall, quien sostuvo que como los españoles no comprendieron hasta qué punto las enfermedades fueron responsables del declive demográfico, una minoría de ellos (siendo el más representativo fray Bartolomé de Las Casas) atribuyó tal fenómeno a la brutalidad de la Conquista. ${ }^{8}$

La historiografía colombiana por su parte ha resaltado en términos generales la relación entre el declive demográfico y ciertas instituciones económicas. Así, por ejemplo, el impacto de los regímenes de la encomienda y la mita ha sido estudiado en cierta medida por autores como Juan Friede, ${ }^{9}$ Germán Colmenares, ${ }^{10}$ Darío Fajardo, ${ }^{11}$ Hermes Tovar Pinzón, ${ }^{12}$ Juan Villamarín, ${ }^{13}$ Luis Enrique Rodríguez Baquero, ${ }^{14}$ Marta Herrera Ángel ${ }^{15}$ y Diana Bonnett Vélez. ${ }^{16}$ Adicionalmente, existen algunas monografías que detallan significativamente casos locales y regionales. ${ }^{17}$

\footnotetext{
${ }^{7}$ James Lockhart, Los nahuas después de la Conquista: historia social y cultural de la población indigena del México central, siglos XVI-XVIII (México: Fondo de Cultura Económica, 1992) 15 y ss.

${ }^{8}$ Matthew Restall, Los siete mitos de la conquista española (Barcelona: Paidos, 2004) 185.

9 Juan Friede, "Algunas consideraciones sobre la evolución demográfica en la Provincia de Tunja", en Anuario Colombiano de Historia Social y de la Cultura 3 (1965): 5-19. Véase también del mismo autor las obras Los Chibchas bajo la dominación española (Bogotá: La Carreta, 1974) y Los Quimbayas bajo la dominación española: estudio documental, 1539-1810 (Bogotá: Banco de la República, 1963).

${ }^{10}$ Germán Colmenares, Encomienda y población en la Provincia de Pamplona: 1549-1650 (Bogotá: Universidad de Los Andes, 1969). Véase también del mismo autor las obras Historia económica y social de Colombia: 1537-1719 (Bogotá: La Carreta, 1978) y La Provincia de Tunja en el Nuevo Reino de Granada: ensayo de historia social, 1539-1800 (Bogotá: Tercer Mundo, 1997).

${ }^{11}$ Darío Fajardo, El régimen de la encomienda en la Provincia de Vélez: población indígena y economía (Bogotá: Universidad de Los Andes, 1969).

${ }^{12}$ Hermes Tovar Pinzón, Marta Herrera Ángel, y Luis Enrique Rodríguez Baquero, Territorio, población y trabajo indígena: Provincia de Pamplona Siglo XVI (Bogotá: Instituto Colombiano de Cultura Hispánicas-Fondo Mixto para la Promoción de la Cultura y las Artes del Norte de Santander, 1998).

${ }^{13}$ Juan Villamarín, Encomenderos and Indians in the Formation of Colonial Society in the Sabana de Bogota, Colombia, 1537 to 1740 (Waltham: Brandeis University, 1972).

${ }^{14}$ Luis Enrique Rodríguez Baquero, Encomienda y vida diaria entre los indios de Muzo: 1550-1620 (Bogotá: Instituto Colombiano de Cultura Hispánica, 1995).

${ }^{15}$ Marta Herrera Ángel, Poder local, población y ordenamiento territorial en la Nueva Granada-siglo XVIII-(Bogotá: Archivo General de la Nación, 1996).

${ }^{16}$ Diana Bonett Vélez, Tierra y comunidad: un problema irresuelto. El caso del altiplano cundiboyacense, Virreinato de la Nueva Granada, 1750-1800 (Bogotá: Instituto Colombiano de Antropología e Historia-Universidad de los Andes, 2002).

${ }^{17}$ Jeanne Mavis Burford de Buchanan, Pueblo, encomienda y resguardo en Facatativá 1538-1852 (Tesis de pregrado en Historia, Bogotá, Pontificia Universidad Javeriana, 1980); Gonzalo Buenahora Duran, $L a$ república de españoles y los pueblos indios del Macizo Colombiano: Almaguer en los siglos XVI, XVII, XVIII (Tesis Maestría en Historia, Bogotá, Universidad Nacional de Colombia, 1997); Héctor Manuel Cuevas Arenas, La republica de indios: un acercamiento a las encomiendas, mitas, pueblos de indios $y$ relaciones interestamentales de en Cali. Siglo XVII (Cali; Archivo Histórico de Cali, 2005); David Fernando Echeverri Burbano, Usaquén del poblado indígena al desarraigo. Politicas de agregaciones
} 
La mayoría de los trabajos que existen sobre los castigos en la América española refieren a las guerras de Conquista. Son bastante conocidos los episodios violentos de la época que han quedado plasmados en la historiografía. Pero quizás aquí sean bastantes útiles las consideraciones de German Colmenares cuando hablaba del universo mental que debió existir durante la Conquista, y que condujo a la imposición de un nuevo sistema económico y político. Según Colmenares, la tortura era un instrumento legal con ciertos rasgos de legalidad. Así, desde el pensar de los conquistadores la muerte de los indios había sido un simulacro de juicio necesario para pacificar la tierra y obtener sus servicios. ${ }^{18}$

No obstante, también se ha llegado a considerar que era normal que los encomenderos ejercieran el poder de un modo que podría parecer violento y arbitrario; el problema surgía cuando los castigos físicos excedían ciertos límites, poniendo en riesgo la vida del castigado. Así, "la violencia tenía limites que un buen encomendero conocía y evitaba transgredir". Según Jorge Augusto Gamboa Mendoza, los casos más graves se presentaron entre los años de la Conquista y la década de 1560, en los que aparecen referencias a torturas y homicidios; posterior a aquella fecha se habla de golpes, azotes, humillaciones y prisiones. A partir de entonces los nativos se fueron adaptando al sistema judicial español, dando dos resultados paralelos: por un lado, se multiplicaron las denuncias contra los encomenderos, y de otra, las comunidades se acostumbraron a obedecer y tributar a los nuevos amos. Interesa particularmente que relata la importancia de los castigos en el contexto del establecimiento de la encomienda y la imposición de tributos durante el siglo XVI. ${ }^{19}$

Juan David Montoya Guzmán y José Manuel González Jaramillo relatan también como los indios de algunas provincias de Antioquia huían debido a los malos tratos de los encomenderos. Allí las encomiendas se debatían entre la pérdida de fuerza laboral y la recuperación constante que generaban nuevas expediciones militares. Aparecen algunas referencias a golpes con palos y azotes. Según los autores, la violencia constituyó el principal medio de sujeción de la mano de obra, haciendo sumamente móvil el trabajo indígena. ${ }^{20}$ Sin embargo, no brindan detalles sobre los castigos.

Quien sí brinda algunos detalles es Mauricio Alejandro Gómez Gómez, que sin desmeritar el impacto de las enfermedades se ocupa brevemente de los castigos. Según el autor, con los castigos se buscaba aumentar el ritmo de la producción

\footnotetext{
de pueblos de indios en el siglo XVIII un estudio de caso (Tesis pregrado en Historia, Bogotá, Pontificia Universidad Javeriana, 2006); entre otros.

${ }^{18}$ Germán Colmenares, "La aparición de una economía política de las Indias", en Revista Universidad de Antioquia, 220 (abril-junio de 1990): 31-44.

${ }_{19}$ Jorge Augusto Gamboa Mendoza, El cacicazgo muisca en los años posteriores a la Conquista: del psihipqua al cacique colonial (1537-1575) (Bogotá: Instituto Colombiano de Antropología e Historia, 2013) 501 y ss.

${ }^{20}$ Juan David Montoya Guzmán y José Manuel González Jaramillo, Indios, poblamiento y trabajo en la provincia de Antioquia, siglos XVI y XVII (Medellín: Universidad Nacional de Colombia, 2010) 61, 76, 82,108 y 113.
} 
minera y agrícola. En ese contexto, la escenificación del dolor era "una forma de occidentalización que se quedaba en el recuerdo y determinaba la forma de comportamiento de los indios". Siguiendo a Alejandra Araya Espinoza, se afirma que el castigo permitía dar a entender que lo "menos noble" debía sujetarse a lo "más noble", es decir, "el siervo a su señor". ${ }^{21}$

Otros estudios tratan de abordan los castigos que se infringían a los indios en el contexto del proceso de evangelización. Estos estudios evidencian que hubo, en cierta medida, una reformulación de la tipología penal, adecuando los castigos a la realidad cultural de las poblaciones andinas. Entre las penas figuraban la trasquilación, los azotes, la vergüenza de portar una cruz al cuello o pasear sobre un animal por todo el pueblo, la confiscación de bienes, el destierro, el trabajo en las galeras, la cárcel, la prestación de servicios en los conventos u hospitales, o la abjuración. ${ }^{22}$ Para el caso colombiano se resaltado la idea del choque de imaginarios cosmológicos, y las subsecuentes penas y castigo admitidos por la legislación de la época contra los grupos dominados. Según Diana Luz Ceballos Gómez, los delitos y sus castigos se hallaban bien delimitados por los jueces en la sociedad del Nuevo Reino de Granada. ${ }^{23}$

Groso modo puede decirse que la historiografía no ha abordado profusamente el problema de los castigos en el contexto de los regímenes de trabajo. Aquí se enuncia como hipótesis la idea de que los servicios personales y los castigos impuestos bajo la encomienda posibilitaron luego que otros agentes privados pudieran aprovecharse de la fuerza de trabajo indígena y someterla con otras formas de organización. Falta profundizar que cambios y permanencias se presentaron en los castigos laborales entre el primer régimen y los subsiguientes. Como se argumentará aquí, este problema toma importancia en la medida que relaciona los "malos tratos" con las huidas de los pueblos y distritos mineros, la intensidad de los regímenes de trabajo, las enfermedades y el fatalismo (o "desgano vital").

En este sentido, el objetivo de este artículo es tratar de abordar las relaciones entre las condiciones de trabajo y los castigos. En un primer momento se procurará ubicar al lector en el contexto geográfico y etno-demográfico en el cual se desarrollaron los acontecimientos narrados más adelantes. También se incluye una

\footnotetext{
21 Mauricio Alejandro Gómez Gómez, Del chontal al ladino: hispanización de los indios de Antioquia según la visita de Francisco Herrera Campuzano, 1614-1616 (Medellín: Universidad de Antioquia, 2015) 116 y ss. Véase también el texto de Alejandra Araya Espinoza, "El castigo físico: el cuerpo como representación de la persona, un capítulo en la historia de la occidentalización de América, siglo XVIXVIII", Historia 39. 2 (2006): 364.

${ }_{22}$ Macarena Cordero Fernández, "Las penas y los castigos para la idolatría aplicados en las visitas de idolatría en Lima durante el siglo XVII", Revista de Estudios Histórico-Jurídicos 32 (2010): 351-379. Véase también obras como la de Pablo de Arriaga, Extirpación de la Idolatría en el Perú (Cuzco: Centro de Estudios Regionales Andinos Bartolomé de las Casas, 1999) y Alfredo Alvar Ezquerra, La Inquisición Española: 1478-1834 (Madrid: Akal, 2009).

${ }^{23}$ Véase las obras de Diana Luz Ceballos Gómez, Hechicería, brujería e inquisición en el Nuevo Reino de Granada: un duelo de imaginarios (Medellín: Universidad Nacional de Colombia, 1995) y Quyen tal haze que tal pague: sociedad y prácticas mágicas en el Nuevo Reino de Granada (Bogotá: Ministerio de Cultura-Colcultura, 2002); Véase también el trabajo de Jaime Humberto Borja Gómez, Inquisición, muerte y sexualidad en el Nuevo Reino de Granada (Bogotá: Ariel, 1996).
} 
breve referencia a la legislación indiana. Seguidamente se examinará cuáles eran los castigos que infringieron los encomenderos a los indios de la Provincia en la primera mitad del siglo XVII. Luego se tratará de detallar los malos tratos que impusieron agentes sociales como los hacendados, estancieros y mineros en la segunda mitad del siglo XVII a través de instituciones como el concierto agrario y las conducciones a las minas. Para tal efecto se han examinado exhaustivamente los expedientes de las Visitas de la Tierra (de 1602, 1623, 1641 y 1657) así como algunas solicitudes y quejas que presentaban los indios. A partir de tal información se ha procurado exponer los casos más representativos de castigos laborales.

\section{Contexto geográfico y etno-demográfico ${ }^{24}$}

La provincia de Pamplona se hallaba enclavada al nororiente de la hoy denominada cordillera oriental colombiana; fue el espacio jurisdiccional de la ciudad de Pamplona, fundada en 1549 por las huestes lideradas por Pedro de Ursúa y Ortún Velasco. Una vez se estableció el cabildo se realizaron algunas expediciones que tuvieron el propósito de asegurar la mayor cantidad posible de encomiendas. Posteriormente el hallazgo de yacimientos auríferos en los ríos de Oro y Surata y Paramo de Vetas a partir de 1551 aseguró la formación de su espacio de producción. A ello también contribuyó el descubrimiento de minas en La Montuosa para 1601. En los años siguientes, una cantidad significativa de encomenderos exigió a los caciques el envío de indios lavadores a las minas y productos para su abastecimiento.

Los españoles percibieron en las comarcas circunvecinas a la ciudad comunidades nativas que denominaron homogéneamente como "chitareros". Sin embargo, no existió unidad política ni jerarquía centralizadora, tratándose más bien de grupos diversos ligados por vínculos lingüísticos y de parentesco o que compartían pautas de poblamiento. La documentación histórica sugiere la existencia de "caciques", "capitanes" o "indios principales" locales de carácter hereditario; la sucesión recaía al parecer en el hijo mayor o en sobrinos maternos. En algunas comunidades, los indios admitieron que realizaban labranzas o pago de tributos en mantas como reconocimiento de estos jefes locales. La mayoría de estas comunidades producían maíz, papa, bija (achiote), ahuyama, plátano, calabaza, habas, fríjol, yuca, sal, mantas, mochilas, cabuyas, entre otros productos.

Con el establecimiento del dominio español devino su declive demográfico. Germán Colmenares calculó en más de 31800 indios el total de la población nativa durante la visita de Cristóbal Bueno de 1559, unos 20800 en la de Tomás López de 1560, 8863 en la de Antonio Beltrán de Guevara de 1602, 10149 en la de Juan de Villabona Zubiaurre de 1623 y 4523 en la de Diego Carrasquilla Maldonado de

\footnotetext{
${ }^{24}$ Germán Colmenares, Encomienda y población 12 y ss. Armando Martínez Garnica y otros, "Las categorías jurídicas de los procesos del poblamiento en la región santandereana”, Anuario de Historia Regional y de las Fronteras, 1 (1995): 119 y ss. Silvano Pabón Villamizar, Los chitareros: prehispánicos habitantes de la antigua Provincia de Pamplona en sierras nevadas (Bucaramanga: Universidad Industrial de Santander, 1992)
} 
1642. Para la visita de Francisco Antonio Moreno y Escandón de 1778 la población total no superaba los 3000 indios. Por su parte Hermes Tovar ha llegado a suponer que población nativa al momento del contacto inicial, en 1532, se acercaba a unas 271000 personas. $^{25}$

Así, las comunidades o "parcialidades" fueron significativamente diezmadas. Mientras que para 1559 y 1560, figuraban más del centenar ( a otras), para 1778 sobrevivían apenas 30. A partir de 1623, las comunidades que habían resistido al impacto de las guerras de conquista, las enfermedades y el régimen de la encomienda fueron "congregadas" y "reducidas" a unos pocos pueblos (Arboledas, Cácota de Velasco, Cácota de Suratá, Carcasí, Chinácota, Chopo, Cúcuta, Guaca, Labateca, Servitá y Silos). También se habían poblado tres asentamientos cercanos a los reales de minas, donde eran enviados indios a extraer el metal dorado (Bucaramanga, Vetas y La Montuosa).

\section{La legislación indiana}

Los regímenes de trabajo impuestos a las comunidades indias posteriores a la Conquista intentaron asegurar la base económica del poblamiento español en la Indias. Los europeos, con la pretensión de adquirir rápidamente las mayores riquezas posibles, sometieron a los indios y los forzaron a realizar diversos trabajos en las casas, campos y minas. Esta circunstancia dio origen a la institución del repartimiento, y posteriormente, la encomienda. No obstante, cuando se evidenció tempranamente la relación entre estas y el fenómeno del declive demográfico, la Corona se preocupó por regular tales instituciones. Esto condujo a las Leyes de Burgos de 1512 y las Leyes Nuevas de $1542 .{ }^{26}$ A partir de este marco legislativo se propuso, en segunda mitad del siglo XVI, la creación de asentamientos nucleados donde los indios recuperaran su modo de vida tradicional: los pueblos de indios. Ello habría de propiciar la concentración de la fuerza laboral nativa.

Ese conjunto normativo, al igual que toda la legislación posterior, tenía como propósito el "buen tratamiento" y "conservación” de los aborígenes del Nuevo Mundo. Fue así como se prohibió la esclavitud de los indios, su venta, la práctica del rescate, el servicio de cargadores, el traslado a parte remotas, la pesca de perlas, entre otras. ${ }^{27}$ Todo esto con la insistencia en considerar a los naturales de las Indias como "personas libres" y "vasallos” de la Monarquía hispánica. Dos preocupaciones

\footnotetext{
${ }^{25}$ Colmenares, Encomienda y población 43-51. Véase también Historia económica 92-104. Tovar Pinzón y otros, Territorio, población 67 y ss.

${ }^{26}$ Richard Konetzke, América latina II. La época colonial (México: Siglo XXI, 1972) 161-175. Véase también la obra de Silvio Arturo Zavala, La encomienda indiana (México: Porrúa, 1973). Para el caso colombiano puede consultarse Hermes Tovar Pinzón, La estación del miedo o la desolación dispersa: el Caribe colombiano en el siglo XVI (Bogotá: Ariel, 1997)

${ }^{27}$ Germán Colmenares y Jorge Orlando Melo, Lecturas de historia colonial II: las Leyes Nuevas y su promulgación en la Nueva Granada: 1542-1550 (Bogotá: Universidad de los Andes, 1968).
} 
se vislumbran en los textos legislativos; por un lado, que los indios devengaran una retribución salarial por los trabajos realizados a los españoles (pudiendo satisfacer sus requerimientos económicos, y aún más, las exigencias fiscales del Estado), ${ }^{28} \mathrm{y}$ de otro, que no recibieran "malos tratamientos" de parte de los encomenderos, funcionarios regios o particulares.

En esta dirección se orientaban la Leyes del Título X del Libro VI de la Recopilación de Leyes de los Reinos de las Indias. ${ }^{29}$ Así, la Ley segunda se encaminaba a que las justicias averiguaran y castigaran "los excesos y agravios" que los indios padecían: "con tal moderación y prudencia, que no dejen de servir y ocuparse en todo lo necesario, y que tanto conviene a ellos mismos y a su propia conservación, ajustando en el modo de su servicio y trabajo, que no haya exceso ni violencia, ni dejen de ser pagados". El texto sugiere, por un lado, las relaciones entre las exigencias económicas y los malos tratamientos, y de otra, la consideración de que era un hecho común en toda la América española. Por esto último, la Ley tercera de la Recopilación, emitida en 1563 en las Ordenanzas de Felipe II a las Audiencias fue ratificada por Felipe IV en 1635. Esta había dispuesto que los Virreyes, presidentes y Oidores informaran "de los excesos y malos tratamientos" infringidos a los indios de la Corona o encomendados a particulares.

Una lectura preliminar de la documentación a lo largo de todo el periodo colonial permite comprobar que la realidad era ajena a la legislación. En los expedientes de Visitas a la Tierra, realizadas por los funcionarios de la Real Audiencia de Santa fe durante el siglo XVII, figuran numerosas referencias a incumplimiento en la paga de las retribuciones salariales y castigos laborales. Tales "malos tratos" eran infringidos a los indios no sólo de parte de los otrora conquistadores o sus descendientes (en el marco de la institución de la encomienda) sino también por particulares que comenzaban a usufructuar la mano de obra indígena (bajo la forma de concierto agrario y conducciones a las minas de oro de la provincia de Pamplona).

Aquí interesa particularmente que no es el Estado monárquico o la Iglesia quienes castigan (como en el caso de las prácticas y creencias que contravenía la religión hegemónica), sino agentes privados. Los castigos examinados aquí iban en contra de la legislación aparentemente protectora del indio, pero acentuaban su sometimiento al sistema económico y los regímenes de trabajo de la época. Tales castigos recalcaban la situación de desplazamiento de los indios a los espacios neurálgicos de conflicto económico: las ciudades, las estancias, las haciendas, los distritos mineros.

\footnotetext{
${ }^{28}$ Colmenares y Melo. Véase también de los mismos autores la obra Lecturas de historia colonial III: el problema indígena en el periodo colonial (Bogotá: Universidad de Los Andes, 1969).

${ }^{29}$ Véase: Recopilación de Leyes de los Reinos de las Indias Vol. 2 (Madrid: Consejo de la Hispanidad, 1948) 50 y ss.
} 


\section{Condiciones de trabajo y castigos bajo el régimen de la encomienda}

La encomienda indiana como institución surgida de la Conquista de las comunidades indígenas imponía una serie obligaciones tanto para los indios, como para los encomenderos. A partir de la Leyes Nuevas de 1542 se estipuló que los nativos tributasen determinados trabajos y productos de la tierra para el sostenimiento básico de los conquistadores beneficiarios de la institución, en tanto que éstos últimos quedaban obligados a darles buen tratamiento e instruirlos en la fe católica para que alcanzaran la salvación ${ }^{30}$. De modo que la encomienda sintetizó tres objetivos fundamentales del establecimiento del dominio español sobre las comunidades nativas: primeramente, asegurar y regular la exacción de las riquezas de los conquistados en trabajo y productos; segundo, difundir la fe católica como legitimadora del orden socioeconómico y político; y finalmente, afianzar el poder de la Corona sobre sus vasallos indios.

Ahora bien, el régimen de la encomienda fue especialmente severo no solo por cuanto impuso múltiples exacciones económicas, sino también porque menoscabó psicológicamente a las comunidades nativas con numerosos castigos físicos y formas de violencia verbal. En las declaraciones que daban los indios a los Interrogatorios ${ }^{31}$ y Autos de Cargos -insertos en los expedientes de las Visitas-se encuentran continuas referencias a "mojicones", "coces", "palos" y expresiones soeces. Todas estas prácticas se dirigían a acentuar las disciplinas laborales y la sumisión de los indios en múltiples aspectos de la vida cotidiana. Aquí particularmente se trata de evidenciar las relaciones entre las tensiones laborales y los castigos.

Así por ejemplo, un cacique del repartimiento de Bochaga-Chucarima, testificó en 1602 que su encomendero Alonso Carrillo de Orozco solía insultar a los naturales: "cuando los indios que trabajan les piden que les dé [de] comer, les dice que coman cagajones y yerba, que son bestias y caballos", "o puercos que han de comer tanto"*. Al parecer el encomendero les reñía constantemente. Por los mismos motivos le formularon Cargos en relación a la cuadrilla que tenía en el Real de Minas de Vetas. Según se anotó en el expediente, cuando los indios "muertos de hambre y con necesidad" acudían a él, les decía: "perros, busca estiércol de caballo y suciedades, y hace mazamorra y come". El Visitador -Antonio Beltrán de Guevara, Corregidor de la provincia de Tunja- registró información adicional al respecto: "los azota y maltrata de obra y palabra, diciéndoles que son unos perros y sus esclavos, dándoles de palos, coces y mojicones porque no les sacan mucho oro". Finalmente también se le formularon Cargos por azotar a otros indios que se fueron a quejar ante

\footnotetext{
${ }^{30}$ Sobre este el aspecto legal de la encomienda véase J. M. Ots Capdequí, El Estado español en las Indias (México: Fondo de Cultura Económica, 1982) 26-27.

${ }^{31}$ Se han trascrito los interrogatorios con los cuales los visitadores de la Real Audiencia realizaron las indagaciones respectivas sobre las relaciones entre blancos e indios; véase Leonardo Fabián García Rincón, "Interrogatorios de las visitas de 1602, 1623, 1641 y 1657 a la Provincia de Pamplona", Anuario de Historia Regional y de las Fronteras 22. 2 (julio-diciembre 2017): 261-277.
} 
el Visitador ${ }^{32}$. El doctrinero fray Francisco de Hinojosa, denunció también que Juan Borrero, cuando fue encomendero de Chiracoca-Cucaraquesa, dada muchos "palos y azotes" a los indios; inclusive, a uno de ellos, le habría dado "muchos mojicones, y [...] malos tratamientos dentro de la misma iglesia". ${ }^{33}$

Pero no solo los encomenderos, sino también sus mayordomos, administradores, capataces y familiares infringían castigos a los indios. Así por ejemplo, en la comunidad de Bochaga-Chucarima había un capataz llamado Gonzalo Ruíz que enviaba a los indios a cortar madera y les hacía "muy malos tratamientos y [...] muchos azotes" El mismo personaje les daba "palos" a los de Tonchalá "cuando faltaba algún indio para ir a trabajar", "haciéndoles salir de sus bohíos muy de mañana"... "cuando no acudían tan presto como él quería, y que esto era de ordinario en él" y "amenazándoles". ${ }^{34}$ De un indio muisca llamado Juan Cucha que servía de administrador de la encomienda de Laberigua-Ocarena-Las Batatas también se dijo que solía apremiar a los indios para "ir a trabajar", "haciéndoles malos tratamientos, dándoles de azotes y palos", sin permitirles descansar los domingos ni días de fiestas religiosas; ello habría sido la causa de "haber acabado y muerto muchos de los indios", siendo su "enemigo capital". ${ }^{35}$ Por su parte, Pedro y Juan de Arévalo, hijos del encomendero de Cúcuta, al parecer maltrataban a los indios, "dándoles de palos, quitándoles sus mujeres, echándose con ellas por fuerza". ${ }^{36}$

De once encomenderos a los que se le formularon Cargos por haber infringido castigos en la visita del oidor Juan de Villabona Zubiaurre de 1623, sobresalían algunos por su dureza: Melchor de Torres, titular de la encomienda Taqueroma, Alonso Carrillo de Orozco de Tonchalá, Gonzalo de Orozco de Chiracoca-Cucaraquesa, Gerónimo Fernández de Peñalosa de Gemara y Juan de Velasco de Bucarica-Guaca. Parecer ser que para la época el castigo más común era la denominada Ley de Bayona, la cual consistía en azotar al indio desnudo con las riendas de un freno de caballo por la espalda y nalgas, habiéndolo sujetado previamente las manos con una cuerda a alguna viga; ocasionalmente se le ponía preso después de los azotes. Tal fue el castigo que aplicó Alonso Carrillo de Orozco a dos indios "porque no habían salido temprano al trabajo". ${ }^{37}$ Casos extremos parecen haber sido los castigos que infringía Juan de Arteaga, administrador de la cuadrilla de Bucarica-Guaca:

\footnotetext{
32 "Tonchalá, Bochaga y Chucarima: diligencias de visita", 1602. Archivo General de la Nación, Colombia, Sección Colonia, Visitas de Santander, 6, D. 1, f. 92 v.-93 v., 99 v.-100 v., 129 r.

* Para facilitar la lectura del texto se transcriben a continuación los testimonios documentales con ortografía moderna.

33 "Cataluna, Moluga, Matagira, otros: diligencias de visita", 1602. Archivo General de la Nación, Colombia, Sección Colonia, Visitas de Santander, 5, D. 2, f. 312 v. 313 r.

34 “Tonchalá, Bochaga y Chucarima: diligencias de visita", 1602. Archivo General de la Nación, Colombia, Sección Colonia, Visitas de Santander, 6, D. 1, f. 99 r., 39 r. y v. 47 r. y v.

35 "Mogotocoro, Loatá, Batatas, otros: diligencias de visita", 1602. Archivo General de la Nación, Colombia, Sección Colonia, Visitas de Santander, 5, D. 3, f. 719 v.-731 v

36 “Taqueroma y Pamplona: diligencias de visita", 1602. Archivo General de la Nación, Colombia, Sección Colonia, Visitas de Santander, 8, D. 10, f. 529 v.

37 "Tonchalá: diligencias de visita", 1623. Archivo General de la Nación, Colombia, Sección Colonia, Visitas de Santander, 9, D. 3, f. 774 v.
} 
[...] pidió a un indio lavador llamado Martín Melchor Báez que le pagase tres pesos de oro en polvo de los jornales de dos semanas, el cual por no tener pesadumbre con él le daba luego los dos pesos y medio de oro en polvo que tenía, los cuales no quiso recibir el dicho Juan de Arteaga; y porque no le daba el medio peso restante el susodicho con ayuda de Andrés Páez de Sotomayor amarraron al dicho Martín Melchor Báez; y teniéndolo así y desnudo lo azotó con las riendas de un freno, dándole como le dio recio muchos azotes por tres veces descansando, de los cuales le alzaron el cuero en las nalgas y espaldas de que le salió mucha sangre; y habiéndole lavado con orines, sal y ají, le tuvo preso en un cepo, donde le tuvo una semana, y después de suelto le pagó y cobró él los dichos tres pesos de oro en polvo de jornales. ${ }^{38}$

Juan de Arteaga había azotado también a un indio lavador llamado Alonso, pero no satisfecho con eso "lo amenazó con enojo que lo había de ahorcar en una horca que muchos días había estaba puesta en el dicho sitio de Bucarica”. El indio al parecer había huido a Guaca sin pagarle la cuota de oro. Un domingo, antes de oír misa, aprovechando que no había autoridad judicial alguna en el sitio, mandó a poner al indio Alonso en un caballo "enjalmado, atadas las manos con una cabuya, y en ellas se le puso una cruz de madera pequeña”, paseándolo por las calles y conduciéndolo a donde estaba puesta la horca. Arteaga mandó al indio que servía de verdugo que lo pusiera en la horca, el cual le dijo que rezara un Paternóster y un Ave María; Alonso no habría podido porque "estaba turbado y temblando de miedo", seguido de lo cual se desmayó. El ruido generado hizo reunir a los demás indios, quienes le rogaron a Arteaga que lo quitara de la horca, pero también se rieron "como que se había hecho burla". ${ }^{9}$

Otro ejemplo que se puede resaltar es el castigo que infringió Matías de Tolosa, mayordomo del repartimiento de Izcala de Nicolás de Palencia, a un indio llamado Tomás:

[...] el dicho Tomás, indio fiscal, riñó con Teresa, su mujer y con Úrsula, su hermana, porque estaban amancebadas con el dicho Matías de Tolosa, y rompió una manta colorada de algodón y una camisa de ruan que el dicho Matías de Tolosa le había dado a la dicha Teresa india; el susodicho se enojó [con] el dicho Tomás indio, y por esta causa fue a su casa y con un garrote le dio al dicho Tomás muchos palos y lo trató muy mal; y luego hizo que Andrés de Palencia, hijo mayor del dicho capitán Nicolás de Palencia, le volviese a dar como le dio de palos al dicho Tomás, y lo amarró el dicho Andrés de Palencia y le dio más de veinte azotes en presencia del dicho Matías de Tolosa $[\ldots]$ estuvo a la muerte y más de dos meses en la cama $[\ldots]{ }^{40}$

\footnotetext{
38 "Guaca y Bucarica: diligencias de visita", 1622. Archivo General de la Nación, Colombia, Sección Colonia, Visitas de Santander, 11, D. 10, f. 717 r.

39 "Guaca y Bucarica: diligencias de visita”, 1622. Archivo General de la Nación, Colombia, Sección Colonia, Visitas de Santander, 11, D. 10, f. 716 r. y v.

40 "Yzcala: diligencias de visita", 1623. Archivo General de la Nación, Colombia, Sección Colonia, Visitas de Santander, 1, D. 12, f. 842 r.
} 
En 1657, durante la visita del oidor Diego Baños y Sotomayor, también se le formularon cargos a José de Rojas Camacho, encomendero de Ícota-Serquerí. Al parecer, Juan Chicaragua, uno de sus porqueros, "viéndose falto de sustento se fue a los Chiscas", teniendo que ser traído por su capitán; al regresar "cogió al dicho indio y lo amarró, y dio muchos azotes con un freno, y lo puso preso en la cárcel de Pamplona, donde lo tuvo veinte y cuatro horas". Al mismo indio le habría dado luego unos diez y seis azotes porque un macho del arria estaba flaco. Otra vez, "estando dentro de la iglesia de este pueblo dio de mojicones a Pablo, indio" en razón de que una yunta de bueyes del último había hecho daños en los cultivos del primero; el mismo castigo se lo volvió a aplicar porque "no le quería ir a servir". También dio mojicones a otro indio llamado Bartolomé Castro cuando informó al doctrinero que allí morían los indios sin confesión. ${ }^{41}$

Otro personaje con un extenso registro de malos tratamientos contra los indios fue José de Campos, encomendero de Tane: a don Mateo, gobernador, "lo desolló [a] azotes habiéndole metido una palanca dentro de la pierna"; lo mismo hizo con otro indio llamado Estaban, razón por la cual huyó del pueblo; al fiscal Pablo, "estando tocando la oración [...] le dio muchos palos, golpes y porrazos"; al muchacho Felipe, "lo puso preso en una petaca [...] con un candado", ante lo cual huyó (pero luego se vió obligado a volver para que el gobernador se lo quitara); al vaquero Nicolás acusó -falsamente- de ladrón, con lo cual justificó amarrarlo y azotarlo; a Marta, hija de Esteban, "le dio muchos azotes", razón por la cual "estuvo muy mala". De modo que los trataba "siempre muy mal de obra y de palabra, motivando las ausencias". ${ }^{42}$

Podría decirse, ciertamente, que los servicios personales y los castigos impuestos bajo el régimen de la encomienda posibilitaron luego que otros agentes pudieran aprovecharse de la fuerza laboral indígena, pues contribuyó a someter a los indios al sistema económico impuesto por los españoles. De allí que castigos similares fueran luego infringidos por hacendados, estancieros y mineros. Pese a que la legislación de la Corona española prohibía los castigos a los indios, estos fueron constantes y comunes en las relaciones entre blancos e indios.

\section{Trabajos y castigos bajo los regímenes del concierto agrario y conducciones a las minas}

Aunque los descendientes de los conquistadores y primeros pobladores de las provincias indianas procuraran alianzas de tipo matrimonial y diversas estrategias jurídicas para retener las encomiendas, ${ }^{43}$ dejaron de ostentar el monopolio sobre la fuerza laboral india. Con la creación del cargo de Corregidor de naturales a finales del siglo XVI y la política de Corona española de permitir que otros agentes sociales no

\footnotetext{
41 "Cácota de Hontibón: traslado de escribanía”, 1660. Archivo General de la Nación, Colombia, Sección Colonia, Visitas de Santander, 8, D. 1, f. 100 v.-101 v.

42 "Cácota de Hontibón: traslado de escribanía", 1660. Archivo General de la Nación, Colombia, Sección Colonia, Visitas de Santander, 8, D. 1, f. 111 r.-112 v.

${ }^{43}$ Colmenares, Encomienda y población 26-29.
} 
encomenderos pudieran acceder a la mano de obra india, puede decirse que el modelo de la encomienda entró en crisis. Estos agentes fueron, en primer lugar, los familiares o conocidos de los antiguos encomenderos que se dedicaban a empresas agrícolas y mineras. En segundo lugar, figuraban individuos que se hicieron alguna posesión agraria (estancia o hacienda) cercana a los pueblos de indios o que se dedicaban a la explotación metalífera en los distritos mineros.

La posibilidad de valerse de los indios para actividades agrarias y mineras estaba determinada por dos formas de organización del trabajo indígena: el concierto agrario y las conducciones a las minas, las cuales eran adaptaciones de la mita en la Provincia de Pamplona. Si bien coexistieron, la encomienda fue desplazada por el concierto y las conducciones; empero, mientras la primera había aspirado a ser un monopolio de la fuerza laboral india -adquirido a raíz de las condiciones de la conquista-, las otras dos procuraron convertirse en formas de acceder a tal fuerza por parte de múltiples intereses privados - propiciadas a partir de la legislación casuística de la Corona-. Así, con la configuración de estos modelos de trabajo indígena asalariado se pretendía resolver de forma definitiva el conflicto entre la Corona y los encomenderos. ${ }^{44}$ No obstante, muchas de las tensiones socio-laborales del régimen encomendero (como el problema del incumplimiento en los pagos y los castigos) fueron legadas a los otros dos modos de organización del trabajo.

Así, por ejemplo, el capitán don Pablo de Meneses Toledo, Fiscal protector de los naturales, informaba en 1657 que estaban concertados con Francisco de Ayala, dueño de una estancia en el sitio de Bábega, una cantidad indeterminada de gañanes de tal comunidad, Loatá y Silos. Allí, las condiciones del trabajo no eran las mejores, pues los hacía trabajar desde "antes que salga el sol hasta después de anochecido". Adicionalmente les hacía "malos tratamientos, así de obra como de palabra, tirándoles con piedras y palos", "dándoles bofetadas, coces", y diciéndoles que eran "unos perros borrachos, [...] que no quieren servir". Adicionalmente, una mestiza llamada Juana Rodríguez, que cumplía funciones de ama de llaves, les quitaba "muchas partes de las raciones a los dichos concertados". Esta también les infringía malos tratamientos; a una india, habiéndola metido desnuda en un aposento, "con un freno le dio muchos azotes, y después cogió un palo y le dio con él muchos palos, remeciéndola de los cabellos, bañándola en sangre [...] de las narices y boca". El fiscal resumió que los mencionados infringían "muchos agravios y extorsiones". ${ }^{45}$

Tres años después, un indio llamado Diego, de la encomienda de MogotocoroSisota, se quejó por medio del Protector y administrador de los naturales, Pedro de Villarreal, que su encomendero los había sacado desde niño y llevado a un hato que tenía en la provincia de Tunja, "sirviéndose de él y debiéndole pagar su trabajo" como estaba dispuesto. El indio aseveraba que sólo le habían dado tres patacones y "muchos agravios y malos tratamientos por mano de Juan Jaimes, hijo del dicho encomendero".

\footnotetext{
${ }^{44}$ Fajardo, El régimen de la encomienda 5.

45 "Indios de Silos: su Protector denuncia malos tratos", 1657. Archivo General de la Nación, Colombia, Sección Colonia, Caciques e Indios, 32, D. 66, f. 682 r.-686 r.
} 
A Leonor, una tía suya, la habría retenido contra su voluntad en sus haciendas por siete años junto a su marido, un viejo reservado, "sirviéndose de ellos sin pagar puntualmente su trabajo"; por tal motivo los indios habrían huido y denunciado la situación. ${ }^{46}$

Los mineros también impusieron a los indios una serie de presiones para maximizar sus beneficios económicos. Las conducciones forzosas eran una de las principales razones del ausentismo en las minas y pueblos. Por ello el cacique de Tutepa afirmó en 1658 que, desde la última visita, la cantidad de naturales de su pueblo se había "menoscabado muchísimo"; estos huían para no ser conducidos a las minas y no volvían por temor a ser $\operatorname{castigados}^{47}$. El cacique de Guaca y otros indios sostuvieron también, en 1677, que un minero llamado José de Espinosa, había ido al pueblo y desplazado a seis familias; los condujo a las minas de La Montuosa Alta, donde estuvieron cuatro meses. Una vez allí los compelía a que pagaran cuatro pesos de oro de demora, "sin que los dichos lo supieran sacar ni lavar por ser una cosa muy dificultosa". Así, "por el temple y mucha necesidad que padecían" se huyeron a Santa fe; al cabo de un año volvieron cuatro familias, y de los otros "no se supo más de ellos". El mismo relato sucedió teniendo por protagonista a Andrés de Orozco Carrillo. ${ }^{48}$ Por otra parte, un capitán indio de Servitá denunció que el alcalde de Minas de Vetas solía enviarles jueces con crecidos salarios que les quitaban lo que devengaban, "haciéndoles muchas molestias y castigos, y llevándolos amarrados como si hubieran cometido delito"; por ello se habrían ausentados algunos indios con sus mujeres. Solicitaba frenar tales "agravios y extorsiones". ${ }^{49}$

Para 1681, los caciques del pueblo de Silos solicitaron que fueran exonerados de ir conducidos a las Vetas de Pamplona, pues, aunque habían ganado una provisión de reserva, en la práctica eran compelidos a servir, habiendo "padecido muchos agravios". El cacique de Tutepa particularmente se quejaba de que un minero llamado Antonio de Velasco hizo conducción de indios a las minas. Una vez allí, eran repartidos por un individuo nombrado Martín de Meaurio a favor de Velasco y sus paniaguados. Meaurio era al parecer amigo personal del alcalde de minas, lo que le habría permitido cometer algunas injurias a los indios. El cacique Juan Chocontá declaró al respecto:

¿qué jurisdicción tiene dicho Martín de Meaurío para tratarnos como esclavos, teniendo hechas cantidad de cormas de madera pesada, con fuertes cerraduras, echándoselas a los que tienen alguna flojedad en el trabajo por no haberse ejercitado en las minas, y a otros por sospechas de que no se les huyan, teniéndolos con dichas cormas de día en el trabajo y de noche en un cepo,

\footnotetext{
46 "Indio de Mogotocoro: quejas contra encomendero", 1660. Archivo General de la Nación, Colombia, Sección Colonia, Caciques e Indios, 32, D. 85, f. 996 r. y v.

47 "Indios Ylos: exención trabajo minero en Vetas", 1681. Archivo General de la Nación, Colombia, Sección Colonia, Caciques e Indios, 32, D. 64, f. 652 v.-653 r.

48 "Indios de Servitá: trabajan en las minas de La Montuosa", 1677. Archivo General de la Nación, Colombia, Sección Colonia, Caciques e Indios, 47, D. 19, f. 965 v. 966 r. 967 r.

49 "Indios de Servitá: trabajan en las minas de La Montuosa", 1677. Archivo General de la Nación, Colombia, Sección Colonia, Caciques e Indios, 47, D. 19, f. 970 r.
} 
trasquilándolos y azotándolos severamente? [...] uno de ellos, llamado Lucas, de la encomienda de Tutepa, murió en la prisión y otro, llamado Mateo, de la encomienda de Bábega, habiendo hecho fuga con una corma y quitado el cabello su encomendero porque no le hiciera cargo del dicho indio, enviando por él para conducirlo a dichas minas se precipitó de una cabalgadura mansa en una ladera y se hizo pedazos, y se debe presumir lo hizo por no padecer la muerte cual a que estaba sujeto, los otros dos se ausentaron con cormas y trasquilados [...]; sólo han vuelto cinco con otros agravios de malas pagas y raciones, como estar dicho Martín de Meaurío y los demás mineros comprando el maíz a veinte reales y dándonoslo a razón de cuatro pesos, en todo obrando con nosotros sin ninguna piedad y como si no fuéramos cristianos. ${ }^{50}$

Al parecer, los diversos tipos de mita fueron suprimidos en el segundo cuarto de siglo XVIII, cuando los indios dejaron de ser los únicos proveedores de mano de obra. Se sabe que para las regiones centrales del Nuevo Reino de Granada el concierto agrario compulsivo se suprimió en 1720 y la mita minera en 1729 , en tanto que la urbana había sido abolida ya para 1741. Así, al disminuir la población indígena se modificaron los regímenes laborales a los cuales estaba sometidas las comunidades. ${ }^{51}$ Desafortunadamente, no se sabe en qué momento estas políticas comenzaron a ser efectivas en la Provincia de Pamplona. Sea como fuere, estas instituciones económicas lesionaron enormemente la cohesión social de las comunidades indias, impidiendo que pudieran recuperarse demográficamente una vez había entrado en crisis el régimen de la encomienda.

\section{Reflexiones finales}

Con las visitas de la tierra, la creación de ciertos cargos (como el de corregidor y protector de naturales) y el establecimiento de los funcionarios en algunos lugares importantes de la geografía de la época, los nativos fueron conociendo la legislación indiana y apelaron progresivamente a diversos amparos jurídicos. Pese a esto, no disminuyó el impacto lesivo de los castigos laborales en la vida de los nativos. Ciertamente el fenómeno de los castigos se interrelaciona directamente con la intensidad de los regímenes de trabajo, razonamiento alimenticio, las huidas y las enfermedades (que debieron ser no solamente físicas sino también socio-psicológicas). Todo ello provocó en gran medida el declive demográfico de las comunidades indias que los estudios históricos han advertido.

Parafraseando a Michael Foucault puede decirse que los castigos laborales -al igual que los trabajos forzados y otras penas físicas- convertían el cuerpo en un "instrumento" o "intermediario"; así, el cuerpo se hallaba "prendido en un sistema de coacción y de privación, de obligaciones y de prohibiciones". Foucault argumenta que el castigo se convierte en una especie de "economía de los derechos suspendidos".

\footnotetext{
50 “Indios Ylos: exención trabajo minero en Vetas", 1681. Archivo General de la Nación, Colombia, Sección Colonia, Caciques e Indios, 32, D. 64, f. 650 r.-651 r.

${ }^{51}$ Marta Herrera Ángel, Ordenar para controlar: ordenamiento espacial y control político en las Llanuras del Caribe y en los Andes centrales neogranadino. Siglo XVIII (Bogotá: Academia Colombiana de HistoriaInstituto Colombiano de Antropología e Historia, 2002) 106, cf. nota 116.
} 
Por ello el castigo físico operaba generalmente acompañado de otros "suplementos punitivos" como el racionamiento alimenticio, el encierro, entre otros modos. En este sentido, las relaciones de poder que operaban sobre el cuerpo lo cercaban, lo marcaban, lo domaban, lo sometían a suplicio, lo obligaban a unas ceremonias. ${ }^{52}$

Siguiendo un poco la idea implícita en el título de la obra de Gibson, aquí se propone comprender los castigos laborales como estrategias de "dominación" que delimitaban la identidad del sujeto hacía sí mismo y hacía la comunidad a la cual pertenecía. Los castigos físicos y verbales, generaba relaciones personales y comunitarias de dominación. Es decir, los efectos del castigo no permanecían únicamente sobre el cuerpo individual, sino que permeaban el cuerpo social. El castigo, un fenómeno bastante generalizado en las sociedades de Antiguo Régimen, le señalaba a los individuos y grupos de individuos su posición dentro de las "estructuras" o "sistemas" político-administrativo y legislativo, social, económico y cultural. Así, el castigo laboral subsumía al indio en la Monarquía hispánica, en el sistema mercantilista de la época, en la sociedad estamental indiana, e inclusive, en el universo cristiano dividido entre el cielo, purgatorio e infierno.

\section{Bibliografía}

\section{Fuentes primarias}

\section{Fuentes de archivo}

Archivo General de la Nación, Colombia (AGNC), Fondo Caciques e indios, Sección Colonia.

Archivo General de la Nación, Colombia (AGNC), Fondo Visitas de Santander, Sección Colonia.

\section{Libros}

Recopilación de Leyes de los Reinos de las Indias. Madrid: Consejo de la Hispanidad, 1948, Vol. 1 y 2.

\section{Fuentes secundarias}

\section{Libros}

Alvar Ezquerra, Alfredo. La Inquisición Española: 1478-1834. Madrid: Akal, 2009.

Arriaga, Pablo de. Extirpación de la Idolatría en el Perú. Cuzco: Centro de Estudios Regionales Andinos Bartolomé de las Casas, 1999.

\footnotetext{
${ }^{52}$ Michael Foucault, Vigilar y castigar: el nacimiento de la prisión (Buenos Aires: Siglo XXI, 2002) 13, 17 y 26 .
} 
Bonett Vélez, Diana. Tierra y comunidad: un problema irresuelto. El caso del altiplano cundiboyacense, Virreinato de la Nueva Granada, 1750-1800. Bogotá: Instituto Colombiano de Antropología e Historia-Universidad de los Andes, 2002.

Borja Gómez, Jaime Humberto. Inquisición, muerte y sexualidad en el Nuevo Reino de Granada. Bogotá: Ariel, 1996.

Ceballos Gómez, Diana Luz. Hechicería, brujería e inquisición en el Nuevo Reino de Granada: un duelo de imaginarios. Medellín: Universidad Nacional de Colombia, 1995.

Ceballos Gómez, Diana Luz. Quyen tal haze que tal pague: sociedad y prácticas mágicas en el Nuevo Reino de Granada. Bogotá: Ministerio de Cultura Colcultura, 2002.

Colmenares, Germán y Melo, Jorge Orlando. Lecturas de historia colonial II: las Leyes Nuevas y su promulgación en la Nueva Granada: 1542-1550. Bogotá: Universidad de los Andes, 1968.

Colmenares, Germán y Melo, Jorge Orlando. Lecturas de historia colonial III: el problema indígena en el periodo colonial. Bogotá: Universidad de Los Andes, 1969.

Colmenares, Germán. Encomienda y población en la Provincia de Pamplona: 15491650. Bogotá: Universidad de Los Andes, 1969.

Colmenares, Germán. Historia económica y social de Colombia: 1537-1719. Bogotá: La Carreta, 1978.

Colmenares, Germán. La Provincia de Tunja en el Nuevo Reino de Granada: ensayo de historia social, 1539-1800. Bogotá: Tercer Mundo, 1997.

Cook, Noble David. Demographic Collapse: Indian Peru, 1520-1620. Cambridge: Cambridge University Press, 1981.

Cook, Sherburne F. y Borah, Woodrow. Ensayos sobre historia de la población: México y el Caribe. México: Siglo XXI, 1977.

Cook, Sherburne F. y Borah, Woodrow. The Indian population of central Mexico, 1531-1610. Berkeley: University of California Press, 1960.

Cook, Sherburne F. y Borah, Woodrow. The population of central Mexico in 1548: an analysis of the Suma de Visitas de pueblos. Berkeley: University of California Press, 1960.

Cuevas Arenas, Héctor Manuel. La república de indios: un acercamiento a las encomiendas, mitas, pueblos de indios y relaciones interestamentales de en Cali. Siglo XVII. Cali: Archivo Histórico de Cali, 2005. 
Denevan, William M. The Native population of the Americas in 1492. Madison: University of Wisconsin Press, 1992.

Fajardo, Darío. El régimen de la encomienda en la Provincia de Vélez: población indígena y economía. Bogotá: Universidad de Los Andes, 1969.

Foucault, Michael. Vigilar y castigar: el nacimiento de la prisión. Buenos Aires: Siglo XXI, 2002.

Friede, Juan. Los Chibchas bajo la dominación española. Bogotá: La Carreta, 1974.

Friede, Juan. Los Quimbayas bajo la dominación española: estudio documental, 1539-1810. Bogotá: Banco de la República, 1963.

Gamboa Mendoza, Jorge Augusto. El cacicazgo muisca en los años posteriores a la Conquista: del psihipqua al cacique colonial (1537-1575). Bogotá: Instituto Colombiano de Antropología e Historia, 2013.

Gibson, Charles. Los aztecas bajo el dominio español: 1519-1810. México: Siglo XXI, 1983.

Gómez Gómez, Mauricio Alejandro. Del chontal al ladino: hispanización de los indios de Antioquia según la visita de Francisco Herrera Campuzano, 1614-1616. Medellín: Universidad de Antioquia, 2015.

Herrera Ángel, Marta. Ordenar para controlar: ordenamiento espacial y control político en las Llanuras del Caribe y en los Andes centrales neogranadino. Siglo XVIII. Bogotá: Academia Colombiana de Historia-Instituto Colombiano de Antropología e Historia, 2002.

Herrera Ángel, Marta. Poder local, población y ordenamiento territorial en la Nueva Granada. Siglo XVIII. Bogotá: Archivo General de la Nación, 1996.

Konetzke, Richard. América latina II. La época colonial. México: Siglo XXI, 1972.

Livi Bacci, Massimo. Los estragos de la conquista: quebranto y declive de los indios de América. Barcelona: Crítica, 2006.

Lockhart, James. Los nahuas después de la Conquista: historia social y cultural de la población indígena del México central, siglos XVI-XVIII. México: Fondo de Cultura Económica, 1992.

Montoya Guzmán, Juan David y González Jaramillo, José Manuel. Indios, poblamiento y trabajo en la provincia de Antioquia, siglos XVI y XVII. Medellín: Universidad Nacional de Colombia, 2010. 
Ots Capdequí, J. M. El Estado español en las Indias. México: Fondo de Cultura Económica, 1982.

Pabón Villamizar, Silvano. Los chitareros: prehispánicos habitantes de la antigua Provincia de Pamplona en sierras nevadas. Bucaramanga: Universidad Industrial de Santander, 1992.

Restall, Matthew. Los siete mitos de la conquista española. Barcelona: Paidos, 2004.

Rodríguez Baquero, Luis Enrique. Encomienda y vida diaria entre los indios de Muzo: 1550-1620. Bogotá: Instituto Colombiano de Cultura Hispánica, 1995.

Tovar Pinzón, Hermes, Herrera Ángel, Marta, y Rodríguez Baquero, Luis Enrique. Territorio, población y trabajo indígena: Provincia de Pamplona Siglo XVI. Bogotá: Instituto Colombiano de Cultura Hispánicas-Fondo Mixto para la Promoción de la Cultura y las Artes del Norte de Santander, 1998.

Tovar Pinzón, Hermes. La estación del miedo o la desolación dispersa: el Caribe colombiano en el siglo XVI. Bogotá: Ariel, 1997.

Villamarín, Juan. Encomenderos and Indians in the Formation of Colonial Society in the Sabana de Bogota, Colombia, 1537 to 1740. Waltham: Brandeis University, 1972.

Zavala, Silvio Arturo. La encomienda indiana. México: Porrua, 1973.

\section{Artículos de revistas}

Araya Espinoza, Alejandra. "El castigo físico: el cuerpo como representación de la persona, un capítulo en la historia de la occidentalización de América, siglo XVIXVIII". Historia 39. 2 (2006): 349-367.

Colmenares, Germán. "La aparición de una economía política de las Indias”. Revista Universidad de Antioquia 220 (abril-junio de 1990): 31-44.

Cordero Fernández, Macarena. "Las penas y los castigos para la idolatría aplicados en las visitas de idolatría en Lima durante el siglo XVII". Revista de Estudios Histórico-Jurídicos 32 (2010): 351-379.

Friede, Juan. “Algunas consideraciones sobre la evolución demográfica en la Provincia de Tunja”. Anuario Colombiano de Historia Social y de la Cultura 3 (1965): 5-19.

García Rincón, Leonardo Fabián. "Interrogatorios de las visitas de 1602, 1623, 1641 y 1657 a la Provincia de Pamplona". Anuario de Historia Regional y de las Fronteras 22. 2 (julio-diciembre 2017): 261-277. 
Martínez Garnica, Armando y otros. "Las categorías jurídicas de los procesos del poblamiento en la región santandereana". Anuario de Historia Regional y de las Fronteras 1 (1995): 103-195.

\section{Tesis, ponencias, documentos y otros Inéditos}

Buenahora Durán, Gonzalo. La república de españoles y los pueblos indios del Macizo Colombiano: Almaguer en los siglos XVI, XVII, XVIII. Tesis Maestría en Historia, Universidad Nacional de Colombia, 1997.

Burford de Buchanan, Jeanne Mavis. Pueblo, encomienda y resguardo en Facatativá 1538-1852. Tesis de pregrado en Historia, Pontificia Universidad Javeriana, 1980.

Echeverri Burbano, David Fernando. Usaquén del poblado indígena al desarraigo. Políticas de agregaciones de pueblos de indios en el siglo XVIII un estudio de caso. Tesis pregrado en Historia, Pontificia Universidad Javeriana, 2006. 